\title{
Eulerian-Lagrangian Simulation of Wood Flour and Wind Distribution During the Impulse-cyclone Airflow Drying Process
}

\author{
Feng Chen, ${ }^{\mathrm{a}, *}$ Yinan Liu, ${ }^{\mathrm{a}}$ Xiaohui $\mathrm{Ni}^{\mathrm{a}}{ }^{\mathrm{a}}$ and Xinghua Xia ${ }^{\mathrm{a}, \mathrm{b}}$ \\ To improve the particle transport computational fluid dynamics models of \\ impulse-cyclone airflow drying systems, a Eulerian-Lagrangian discrete \\ particle model (commercial code ANSYS Fluent 2019 R1) was extended \\ to describe the temperature field, airflow velocity field, and particle \\ distribution in the impulse and cyclone dryers. The results showed that the \\ velocity of the airflow considerably changed after wood flour was added \\ into the system, with an approximate velocity difference between the \\ particles and airflow of $2 \mathrm{~m} / \mathrm{s}$. An increased feed rate led to a backflow \\ area at the bottom of the cyclone dryer, which caused reflux and a long \\ residence time of the wood flour in and near the cyclone dryer. By \\ comparing the calculated temperature, velocity, and time curves with the \\ measured temperature and velocity sensor values, the error between the \\ simulated value and the experimental value was only approximately $15 \%$. \\ The current work verifies that the Eulerian-Lagrangian discrete particle \\ model of the impulse-cyclone airflow drying process established via the \\ computational fluid dynamics simulation method was effective. The \\ conclusion provides a reliable theoretical basis for the technological \\ design of impulse-cyclone airflow drying systems, thus providing a way to \\ optimize the structure of impulse-cyclone airflow drying systems in the \\ future.
}

DOI: 10.15376/biores.17.1.75-93

Keywords: Impulse-cyclone airflow drying system; Particle distribution; Eulerian-Lagrangian; DPM; Wood flours

Contact information: a: School of Art and Design, Taizhou University, Taizhou 318000 P. R. China; $b$ : Faculty of Creative Technology and Heritage, Universiti Malaysia Kelantan, Kelantan 16100 Malaysia;

* Corresponding author: c.f84@hotmail.com

\section{INTRODUCTION}

Wood flour particle transport in multistage drying systems is an important problem in the wood plastic composite industry (Zhou et al. 2019). In impulse-cyclone airflow drying (ICAD) systems, particle-particle collisions and particle-fluid interactions are used to maintain good dispersion and uniformity of moisture content (Chen et al. 2017a). Previous studies on wood flour drying systems primarily focused on a single component, e.g., the impulse dryer, cyclone dryer, or double-cyclone dryer (Jamaleddine and Ray 2011; Alavi et al. 2018). However, the movement of particles between various components has a very strong coupling relationship (Buchholz et al. 2021). For example, the strong gassolid turbulence in an impulse dryer would change the discharge efficiency of a cyclone dryer (Gao et al. 2019). At the same time, the geometric structure of the cyclone dryer would also change the discharge efficiency, thus affecting the pressure balance of the 
drying system (Chen et al. 2017b). Based on the non-uniform and non-linear characteristics of ICAD systems, it is difficult to reflect the overall circulation and transport characteristics of particles through the study of a single component via experimental and empirical methods. Therefore, it is necessary to study it via the numerical simulation method.

Gas-solid two-phase flow, as a typical branch of two-phase flow systems, have attracted considerable attention in recent years (Lin et al. 2020). Computational fluid dynamics (CFD) simulations have become increasingly important, as they may contribute to a better understanding of the complex flow physics involved (Zhe et al. 2017). The numerical simulation of gas-solid two-phase flow includes the Eulerian-Eulerian method and the Eulerian-Lagrangian method (Patel et al. 2017). The Eulerian-Eulerian method, which is suitable for large particle volume concentrations, considers both the particle phase and the continuous fluid as a continuum in Euler coordinates (Zhang et al. 2019). The Eulerian-Lagrangian method calculates the trace of a single solid particle or a group of particles in the flow field (Granados et al. 2016; Fernando et al. 2017). The air-drying process involves complex mechanisms in the multi-stage drying system; however, previous studies have focused on simple single-stage dryers (Jamaleddine and Ray 2011; Alavi et al. 2018). Larsson and Orloff (2001) used impulse drying to increase the water removal rate. Ávila et al. (2014) studied the drying of wet PVC particles with straight pipe air flow and established a relevant heat and mass transfer model. They showed that the model can properly simulate the change in the water content of particles and the air temperature with the height of the drying pipe, which was in good agreement with the actual situation. Mansoori et al. (2004) used a discrete phase model to simulate the gas-solid two-phase system. Their simulation results were consistent with the experimental data (Nakhaei and Lessani 2017). Chu et al. (2014) used Fluent software to study the gas-solid two-phase flow in $90^{\circ}$ bends and cyclone separators, which demonstrated that the Euler model was effective in establishing gas-solid two-phase flow. Bunyawanichakul et al. (2006) used a CFD model to simulate the flow field of a cyclone dryer. The results showed that the RNG $\mathrm{k}-\varepsilon$ turbulence model with hexahedral mesh yielded satisfactory results and the pressure drop across the cyclone dryer chamber was predicted with an error rate of approximately $10 \%$.

To better understand and reveal the motion law of wood flour during the ICAD process, the authors developed a Eulerian-Lagrangian model that accounted for flow field, temperature, airflow velocity, pressure, and particle trajectory. Calculations related to the two-phase flow considered in this study were performed with an ANSYS ICEM CFD (ICEM CFD 2019R1, ANSYS Inc., Canonsburg, PA) for the meshing cyclone airflow system and a Fluent Eulerian-Lagrangian DPM (FLUENT TM 2019R1, ANSYS Inc., Canonsburg, PA) for the simulated drying process. The authors regard the air as a continuous phase and the discrete particles as the sparse phase. The gas phase field was described by the Euler method, and the gas phase governing equation can be described by Eq. 1,

$$
\frac{\partial}{\partial t}\left(\rho_{g} \alpha_{g} \varphi_{g}\right)+\frac{\partial}{\partial x_{j}}\left(\rho_{g} \alpha_{g} \mu_{g} \varphi_{g}\right)=\frac{\partial}{\partial x_{j}}\left[\Gamma_{\varphi} \alpha_{g} \frac{\partial \varphi_{g}}{\partial x_{g}}\right]+\psi_{g}
$$

where $\rho_{g}$ is the air flow density $\left(\mathrm{kg} \cdot \mathrm{m}^{-3}\right), \varphi_{g}$ is the generalized variable (velocity, $\mathrm{m} / \mathrm{s}$ ), $x_{j}$ is the vector of fluid flow to solid, $\Gamma_{\varphi}$ is the diffusion coefficient of the relative generalized variable, and $\Psi_{g}$ is the source term of particle to gas (Giavedoni and Saita 1997).

The authors used the Lagrangian method to calculate the trajectory of the particle group in the flow field, and the variation law of solid particle parameters with the trajectory. 
According to Newton's second law, wood flour inertia is equal to the sum of the individual forces acting on the particles, and its equation under the Lagrangian coordinate system is shown in Eq. 2,

$$
\frac{d V_{g}}{d t}=\frac{18 \mu}{\rho d^{2}} \frac{\delta R_{e}}{24}\left(V_{w}-V_{a}\right)+\frac{g\left(\rho-\rho_{a}\right)}{\rho}+F_{x}
$$

where $V_{w}$ is the particle velocity $(\mathrm{m} / \mathrm{s}), d$ is the projected diameter $(\mathrm{m})$ of the wood flour, $R_{e}$ is the Reynolds number of the particles in the air flow, $\delta$ is the resistance factor between the hot air and particles, and $F_{x}$ is the ratio of the other forces $\left(\mathrm{m} / \mathrm{s}^{2}\right)$ to the particle mass (Saidi et al. 2015).

The air-drying process involves the complex mechanisms of a multi-phase system with mutually coupled multi-processes. previous research used CFD simulations to study the effects of the impulse dryer or cyclone dryer, whereas, no quantitative research has been conducted on the heat and mass transfer between two phases of multi-stage drying system. In this study, the flow field, humidity, temperature, airflow velocity, pressure, and fiber distribution in the impulse-cyclone airflow drying process were mastered by CFD simulation software based on Eulerian-Lagrangian method. Thus, a theoretical basis is provided for the large-scale development of the fiber ICAD system in the future.

\section{EXPERIMENTAL}

\section{Materials}

Poplar wood veneers with sizes ranging from 50 to $100 \mathrm{~cm}$ in length, 30 to $50 \mathrm{~cm}$ in width, and 0.4 to $0.6 \mathrm{~cm}$ in thickness were purchased from the Harbin Yongxu Woodbased Panel Co., Ltd. (Heilongjiang, China). The wood veneers were smashed and milled into poplar wood flour via a mill (FY600, Fuyang Energy Technology Co., Ltd., Xuzhou, China).

The particle sizes ranged from 20- to 40-mesh, 40- to 60-mesh, 60- to 80-mesh, 80to 100-mesh, and 100- to 120-mesh. The length and diameter of the flours were measured using a GE-5 high-definition digital microscope (Shanghai Longfa Optical Instrument Co., Ltd., Shanghai, China). The different meshes of wood flour were placed under the objective lens of the microscope, which was adjusted to present a well-focused image. The wood flour particles on the slide were measured for their length and diameter values using the measurement software of the microscope. Thirty measurements were taken for each mesh segment, and the average aspect ratio of the wood flours was determined. The measured results of the length, diameter, and original moisture content are given in Table 1.

Table 1. Characteristics of the Poplar Wood Flours

\begin{tabular}{|c|c|c|c|}
\hline Property Measured (mesh) ${ }^{1}$ & Length (mm) & Diameter $(\mu \mathrm{m})$ & Length to Diameter Ratio \\
\hline 20 to 40 & $1.78( \pm 0.23)$ & $330( \pm 51)$ & $5.4( \pm 1.95)$ \\
\hline 40 to 60 & $1.53( \pm 0.18)$ & $283( \pm 35)$ & $5.4( \pm 1.61)$ \\
\hline 60 to 80 & $1.36( \pm 0.20)$ & $223( \pm 31)$ & $6.1( \pm 1.87)$ \\
\hline 80 to 100 & $0.94( \pm 0.16)$ & $192( \pm 47)$ & $4.9( \pm 1.44)$ \\
\hline 100 to 120 & $0.64( \pm 0.13)$ & $178( \pm 33)$ & $3.6( \pm 0.97)$ \\
\hline
\end{tabular}




\section{Methods}

Impulse-cyclone airflow drying (ICAD) of poplar wood flour

Poplar wood flour was treated in a high-temperature environment with an MQG50 (Jianda Equipment Co., Ltd., Changzhou, China). The optimal operation conditions for these experiments were selected through preliminary tests (Chen et al. 2017b). The wood flour was first subjected to a drying environment generated using a heat generator, a screw feeder, and an induced draft fan at different temperatures $\left(160,180,200,220\right.$, and $\left.240{ }^{\circ} \mathrm{C}\right)$, inlet air velocities $(9,10,11,12$, and $13 \mathrm{~m} / \mathrm{s})$, and feed rates $(90,105,120,135$, and 150 $\mathrm{kg} / \mathrm{h})$.

At the beginning of the drying test, fresh air was injected into the electric heater to preheat the drying system. After the system was filled with hot air and the inlet temperature was constant, the screw feeder was used to begin injecting the wood flour into the impulse dryer. Under the accelerating and decelerating motion of the wood flour in the impulse dryer, the free water in the wood cell cavity was quickly vaporized within the impulse dryer. The cyclone dryer was used to remove the bound water, which was difficult to dry (Yousaf et al. 2019). The larger flour particles were collected by the air-off layout collector and the finer particles entered the dust collector with the exhaust gas. In order to verify the temperature change and airflow velocity change in the ICAD system during the simulated drying process, temperature measuring thermocouples and velocity sensors were placed at the inlet, straight tube, extension tube, and middle and gas outlet of the drying system.

\section{Theoretical model assumptions}

To simulate realistic results, hypotheses and assumptions were made to simplify the complexity of the simulation process; they are as follows: (1) air was regarded as an ideal gas; (2) the wall of the ICAD system is adiabatic; (3) there was a boundary layer between the wall and the airflow; (4) mass loss from the wood flour impact was ignored; and (5) the inlet velocity of second phase was $0 \mathrm{~m} / \mathrm{s}$. Since wood flour is regarded as nonspherical, a shape coefficient was calculated according to Eq. 3 (Liu et al. 2008),

$$
S_{f}=\sqrt[3]{\frac{9 R h^{2}}{2}} / R+h
$$

where $S_{f}$ is the shape coefficient, $R$ is the wood flour diameter ( $\left.\mathrm{mm}\right)$, and $h$ is the length of the wood flour (mm) (Li et al. 2017b; Zaripov et al. 2018). The length and diameter of the wood flour were set according to the experimentally measured results before drying.

Force analysis on the particle phase of the wood flour

The wood flour moves with the gas phase in the flow field, and its inertial force is shown in Eq. 4,

$$
F_{i}=\pi d_{w}^{3} \rho_{w}\left(\frac{\mathrm{d} u_{w}}{d_{t}}\right) / 6
$$

where $d(\mathrm{~m})$ is the flour projection diameter, $\rho_{w}$ is the density $\left(\mathrm{kg} / \mathrm{m}^{3}\right), u_{w}$ is particle velocity $(\mathrm{m} / \mathrm{s})($ Sun et al. 2011).

In the flow field, the force generated by the fluid on the wood flour is called the drag force. The drag force is the resistance of the wood flour to the rise of the fluid, and the direction of the force is upward. The drag force equation is shown in Eq. 5,

$$
F_{S}=\delta A_{P} \rho g \frac{\left(V_{w}-V_{a}\right)^{2}}{2}
$$


where $F_{\mathrm{s}}$ is the drag force $(\mathrm{N}), \rho$ is the density of air $\left(\mathrm{kg} / \mathrm{m}^{3}\right), A_{p}$ is the vertical projected area of flour $\left(\mathrm{m}^{2}\right), V_{w}$ is the particle rising velocity $(\mathrm{m} / \mathrm{s}), V_{a}$ is the air velocity $(\mathrm{m} / \mathrm{s}), g$ is the gravitational acceleration $\left(\mathrm{m} / \mathrm{s}^{2}\right)$, and $\delta$ is the drag coefficient or resistance coefficient between the air flow and particles, whose functional relationship is shown in Table 2 (Yokosawa et al. 1986; Zhang and Reese 2003). Since the movement of gas in the drying tube belongs to the state of turbulent movement, the gas Reynolds number $(\mathrm{Re})$ was greater than 5000; therefore, the $\delta$ value was 0.44 .

Table 2. The Relationship between the Drag Coefficient and Reynolds Number

\begin{tabular}{|c|c|c|c|}
\hline $\operatorname{Re}$ & 0 to 1 & 1 to 500 & 500 to 15000 \\
\hline$\delta$ & $24 / \mathrm{Re}$ & $24 / \operatorname{Re} 0.5$ & 0.44 \\
\hline
\end{tabular}

The particle gravity is shown in Eq. 6,

$$
F_{g}=V \rho_{m} g
$$

where $F_{g}$ is the particle gravity $(\mathrm{N})$ and $\rho_{m}$ is the particle density $\left(\mathrm{kg} / \mathrm{m}^{3}\right)$.

The buoyancy of the particles was calculated according to Eq. 7,

$$
F_{b}=V \rho_{g} g
$$

where $F_{b}$ is the buoyancy of the particles $(\mathrm{N}), V$ is the volume of the wood flour $\left(\mathrm{m}^{3}\right)$, and $\rho_{g}$ is the gas density $\left(\mathrm{kg} / \mathrm{m}^{3}\right.$ ) (Son and Hur 2002). The resultant force on the wood flour is shown in Eq. 8,

$$
F_{m}=F_{s}+F_{b}-F_{g}
$$

where during the acceleration process, the wood flour is in a stationary state, and $F_{s}$ is taken as a positive value. During deceleration, the $F_{s}$ takes a negative value.

The upward Magnus lifting force generated during the rotation of the cyclone dryer was calculated according to Eq. 9,

$$
F_{\text {Mag }}=\pi d_{p}^{3} \rho \omega\left(V_{w}-V_{a}\right) / 8
$$

where $\omega$ is the rotational angular velocity ( $\mathrm{rad} / \mathrm{s})$ of the wood flour in the air flow (Seifert 2012).

The pressure gradient force is the force caused by the pressure gradient of the flow field on the wood flour (Luo et al. 2017). The expression of the pressure gradient force is shown in Eq. 10,

$$
F_{p}=-V\left(\frac{\partial P}{\partial y}\right)
$$

The flow field has a velocity gradient, so the velocity of the upper and lower sides of the particles is different, which produces a Saffman lift force on the particles, which was calculated according to Eq. 11,

$$
F_{s a f}=1.61(\mu \rho)^{\frac{1}{2}} d_{p}^{2}\left(V_{w}-V_{a}\right)(d u / d y)^{1 / 2}
$$

(Yamoah et al. 2015).

In viscous fluid, the instability of fluid flow causes an instantaneous flow resistance, i.e., the Basset force. It can only be accurately described by calculating the 
relevant indexes of the particle motion time experience. Its theoretical expression is shown as Eq. 12,

$$
F_{\text {Bas }}=1.5 d_{p}^{2} \sqrt{\pi \rho_{g} \mu} \times \int_{0}^{t}\left[\left(d V_{w} / d \tau-d V_{a} / d \tau\right) / \sqrt{t-\tau}\right] d \tau
$$

(Yamoah et al. 2015).

\section{$3 D$ physical model and solver selection}

A functional diagram of the ICAD device is shown in Fig. 1. The impulse dryer is designed as the straight tubes combined with the expansion tubes (Chen et al. 2017b). The straight tube has a $180 \mathrm{~mm}$ diameter and is $7450 \mathrm{~mm}$ in total length. The expansion tube has a $320 \mathrm{~mm}$ diameter and is $2880 \mathrm{~mm}$ in total length. The cyclone dryer is designed as a cylinder with a $720 \mathrm{~mm}$ diameter and is $2550 \mathrm{~mm}$ in height.

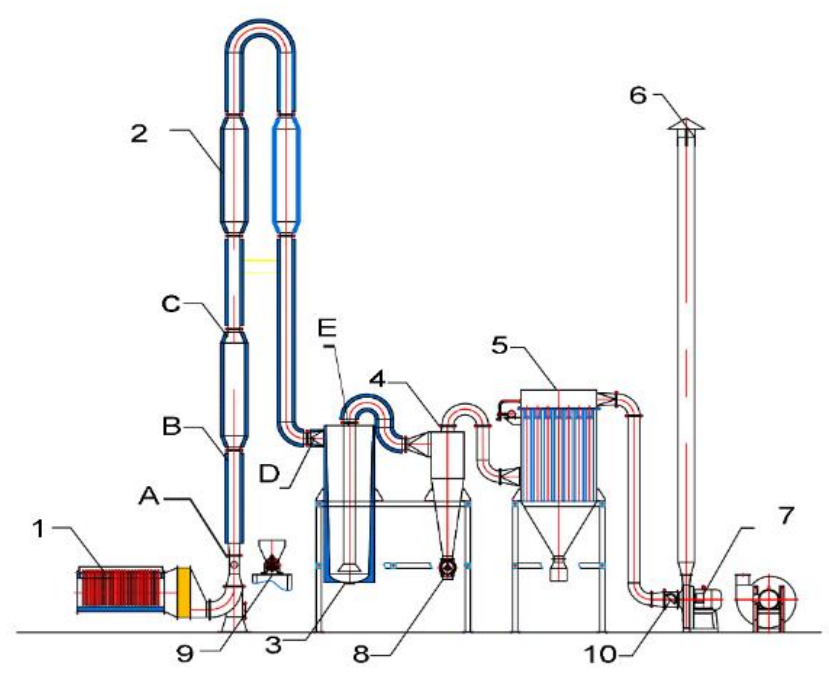

Fig. 1. Functional diagram of an impulse-cyclone airflow drying system: (1) Electric heater; (2) Impulse dryer; (3) Cyclone dryer; (4) Cyclone separator; (5) Dust collector; (6) Exhaust pipe; (7) Induced draft fan; (8) Air-off layout collector; (9) Screw feeder; and (10) Air valve

An ICEM CFD was used to mesh the ICAD system. The impulse dryer was divided into hexahedral structured grids, and the transition corner of the equipment was divided into unstructured grids. The quality of the checked grids was above 0.5 , and the total number of grids was 7099656.

Fluent uses a solver setting to construct the realization of the numerical solution algorithm. A pressure-based solver was applied in this study. The time type parameter was chosen as "steady" and "absolute" for the velocity equation. The effect of gravitational acceleration was considered in the model.

\section{Boundary condition settings}

The initial conditions were as follows: (1) the inlet air velocity was $10 \mathrm{~m} / \mathrm{s}$; (2) the inlet particle velocity was $0 \mathrm{~m} / \mathrm{s}$; (3) the inlet temperature was $200{ }^{\circ} \mathrm{C}$; and (4) the inlet particle temperature was $23{ }^{\circ} \mathrm{C}$. The turbulence intensity value set was calculated according to Eqs. 13 and 14,

$$
R_{e_{\text {inlet }}}=\frac{v d}{\gamma}
$$




$$
I_{\text {inlet }}=16
$$

where the subscript $R_{e_{\text {inlet }}}$ denotes the inlet flow Reynolds number, $\gamma$ is the standard air $\operatorname{viscosity}\left(\mathrm{m}^{2} / \mathrm{s}\right), v$ is the inlet speed $(\mathrm{m} / \mathrm{s})$, and $d$ is the inlet tube diameter $(\mathrm{m})$ (Li et al. 2017a).

The physical parameters, including the density, specific heat capacity, thermal conductivity, and air viscosity, were set according to the standard value, which were provided in Table 3.

Table 3. Gas-solid Two-phase Physical Parameters of the Impulse-cyclone Airflow Drying (ICAD) System

\begin{tabular}{|c|c|c|c|}
\hline \multicolumn{2}{|c|}{ Solid Phase / Wood Flours } & \multicolumn{2}{c|}{$\begin{array}{c}\text { Gas Phase / Air } \\
\text { (Standard Atmospheric) }\end{array}$} \\
\hline $\begin{array}{c}\text { Average particle } \\
\text { size } / \mathrm{d}(\mu \mathrm{m})\end{array}$ & $178 / 192 / 223 / 283 / 330$ & $\begin{array}{c}\text { Density of air } / \rho \\
\left(\mathrm{kg} / \mathrm{m}^{3}\right)\end{array}$ & 0.81 \\
\hline Shape factor & $0.541 / 0.593 / 0.615 / 0.683 / 0.702$ & Viscosity / (Pa.s) & $2.5 \times 10^{-5}$ \\
\hline $\begin{array}{c}\text { Specific heat } \\
\text { capacity } / \mathrm{Cs} \\
\left(\mathrm{KJ} /\left(\mathrm{kg} \cdot{ }^{\circ} \mathrm{C}\right)\right.\end{array}$ & 2100 & $\begin{array}{c}\text { Thermal Conductivity } \\
\left(\mathrm{W} \cdot \mathrm{m}^{-1} \cdot{ }^{\circ} \mathrm{C}^{-1}\right)\end{array}$ & 0.0244 \\
\hline
\end{tabular}

The iterative operation of the multi-phase flow field variables in Fluent is controlled by the sub-relaxation factor, which determines the convergence condition of the calculation. The sub-relaxation factor was calculated by default in this study. When using the separate solver, a pressure-velocity correlation form was used to solve the momentum equation to obtain the velocity field. The pressure field was modified based on the velocity field result.

A simple algorithm was used for the steady flow calculation. The difference calculation algorithm was performed using a first order upwind. The momentum term was set to a second-order upwind. The convergence critical iteration residual criterion was set to 0.001 . In the calculation process, the air without particles was considered as a continuous phase. After initialization, the gas phase flow field was calculated and simulated, and the continuous phase was calculated to convergence after 2598 steps. The poplar wood flours were then used as discrete phase particles to observe the interaction between the airflow and particles in the gas-solid two-phase coupled simulation.

\section{RESULTS AND DISCUSSION}

\section{The Air Velocity Contour of the Impulse-cyclone Airflow Drying (ICAD) System}

Figure 2 shows the air velocity contour of the ICAD system under the experimental conditions, i.e., a gas inlet velocity of $10 \mathrm{~m} / \mathrm{s}$, a feed rate of $0.033 \mathrm{~kg} / \mathrm{s}$, and a particle diameter of $0.223 \mathrm{~mm}$. The airflow in the straight tube was accelerating and the gas velocity gradually stabilized. When the diameter of the expansion tube increased, the airflow velocity decreased (Fig. 2a). There was an obvious velocity gradient where the flow velocity near the wall was low and was largest in the central area; this was due to the boundary layer between the wall surface and the fluid. The velocity distribution changed when the airflow passed through the elbow at the top of impulse dryer (Fig. 2b). The velocity near the inside diameter of the elbow tube was greater than the velocity near the 
outside diameter of the elbow tube. It can be seen from the velocity contour that the maximum speed was $15.8 \mathrm{~m} / \mathrm{s}$ at the elbow of the descending straight line near the cyclone dryer. The larger airflow density and the pressure field led to an increase in the airflow velocity near the inside diameter, which was consistent with the description of Bernoulli's equation.

The airflow entered the cyclone dryer along the tangent line and rotated downward at a low speed; consequently, this increased the retention time of the particles in the dryer (Fig. 2c). Next, the flow accelerated directly to the outlet of the dryer in the inner tube. This affected the trajectory of the wood flour in the airflow field. The velocity near the outside of the dryer was considerably higher than the velocity of the intermediate flow.

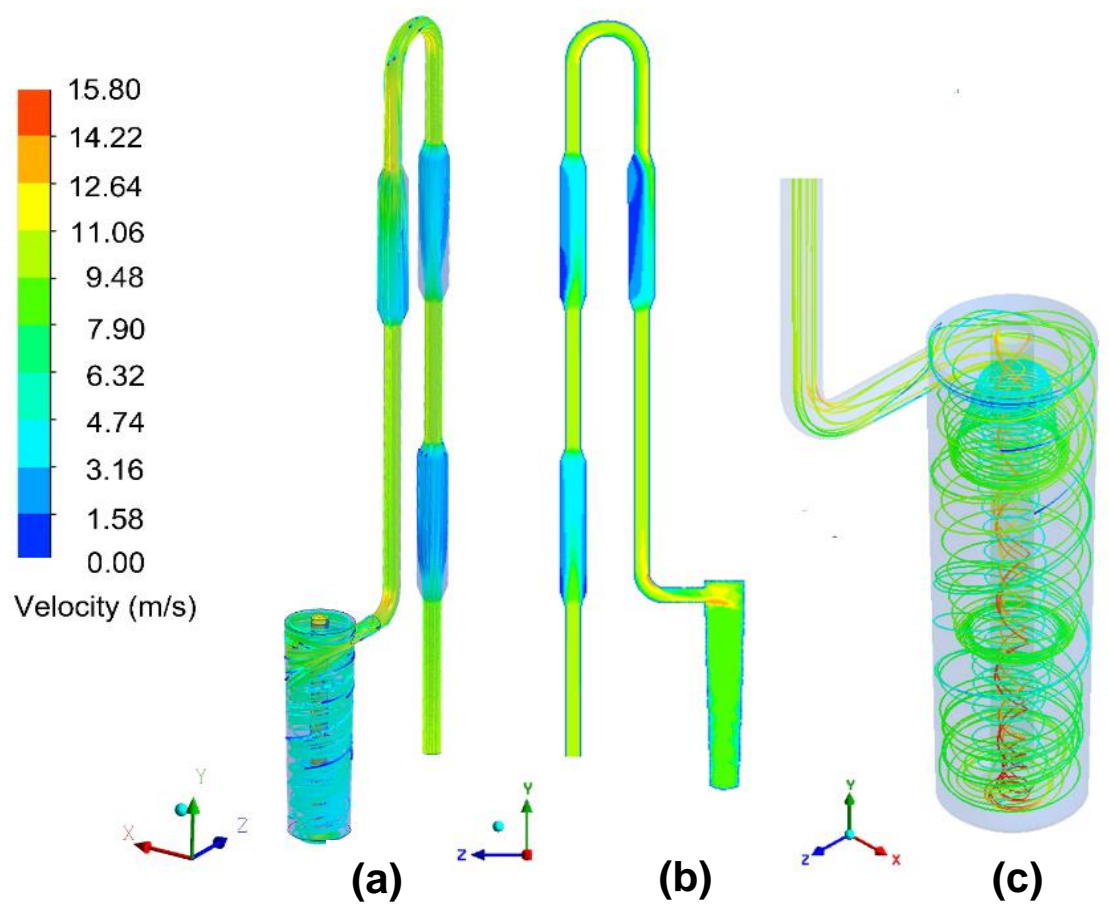

Fig. 2. The air velocity contour of the ICAD system: (a) Airflow velocity contour of ICAD system; (b) Vertical airflow velocity contour at $z=160 \mathrm{~mm}$ of ICAD system; and (c) Airflow velocity contour of cyclone dryer

A change of $0 \mathrm{~m}$ to $8.3 \mathrm{~m}$ in the axis velocity of the impulse dryer was observed with different inlet airflow velocities (Fig. 3). The airflow went from accelerating at $0 \mathrm{~m}$ to $1.7 \mathrm{~m}$, to decelerating at $1.7 \mathrm{~m}$ to $3.5 \mathrm{~m}$, and rapidly accelerating at $3.5 \mathrm{~m}$ to $3.8 \mathrm{~m}$ in a very short time, which indicated that the sudden changes in diameter from the extension tube to the straight tube affected changes in airflow velocity. In the acceleration section of $3.8 \mathrm{~m}$ to $5.2 \mathrm{~m}$, the acceleration range was slow, but the maximum airflow velocity was higher than the maximum airflow velocity in the section of $0 \mathrm{~m}$ to $1.7 \mathrm{~m}$. The airflow velocity of the extension tube was decelerated in the $5.2 \mathrm{~m}$ to $6.8 \mathrm{~m}$ section and the turbulent motion at the inlet velocity of $13 \mathrm{~m} / \mathrm{s}$ was the most intense (Fig. 3a). 


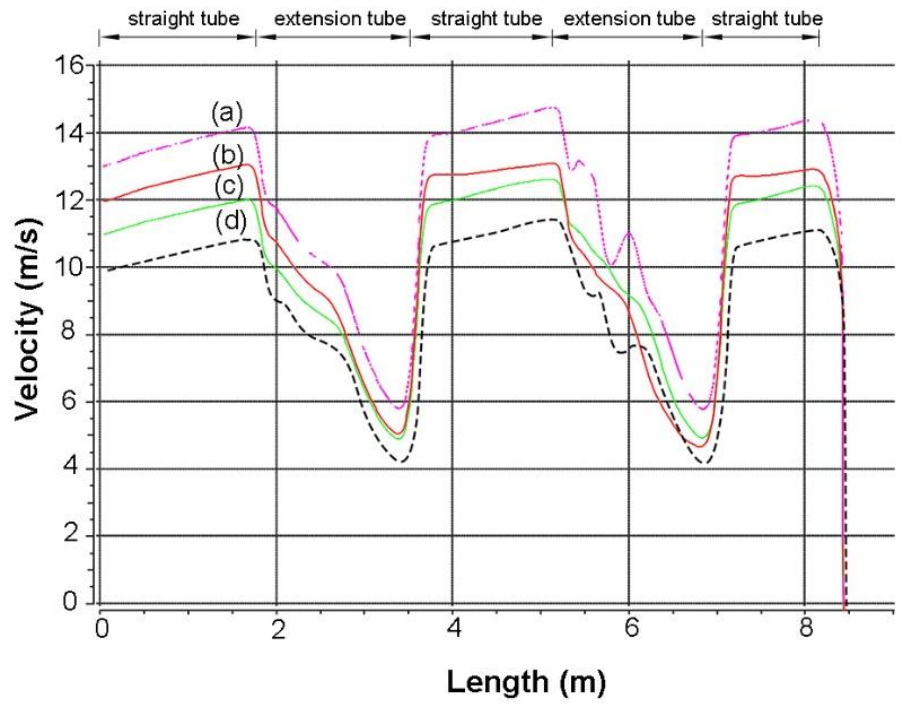

Fig. 3. Airflow velocity change curves at a $y=0-8.4 \mathrm{~m}$ cross-section of the impulse dryer model: (a) Airflow velocity change curves at an air velocity of $13 \mathrm{~m} / \mathrm{s}$; (b) Airflow velocity change curves at an air velocity of $12 \mathrm{~m} / \mathrm{s}$; (c) Airflow velocity change curves at an air velocity of $11 \mathrm{~m} / \mathrm{s}$; and (d) Airflow velocity change curves at an air velocity of $10 \mathrm{~m} / \mathrm{s}$.

The second most rapid acceleration movement occurred at $6.8 \mathrm{~m}$ to $7.2 \mathrm{~m}$. It exhibited close to uniform velocity under inlet velocities of $12 \mathrm{~m} / \mathrm{s}$ at $7.2 \mathrm{~m}$ to $8.2 \mathrm{~m}$; the velocity of airflow became smaller at the $8.2 \mathrm{~m}$ to $8.4 \mathrm{~m}$ section where the airflow entered the elbow.

Because the influence of retaining ring was not considered in the equipment, the partial velocity at the maximum diameter of cyclone dryer was the largest. This is contrary to the results in the literature (Akpinar et al. 2003; Bunyawanichakul et al. 2006), which shows that the baffle ring has a great influence on the air velocity. The next step is to investigate the influence of loading retaining ring on air flow.

\section{The Solid Phase Velocity Contour of the Impulse-Cyclone Airflow Drying System}

Figure 4a shows the airflow velocity distribution of the particles in the impulsecyclone drying flow field obtained via simulation. The maximum airflow velocity of the ICAD system with poplar flour was $13.6 \mathrm{~m} / \mathrm{s}$, which decreased by $2.3 \mathrm{~m} / \mathrm{s}$ compared to the maximum airflow velocity $(15.9 \mathrm{~m} / \mathrm{s})$ without poplar flour. Due to the temperature difference between the poplar flour and the airflow, the airflow transferred heat to the poplar flour. The volume of the airflow was then reduced to a smaller volume, thereby reducing the velocity of the airflow. Since the solid particles occupied a portion of the space in the dryer, the volume fraction of the dryer occupied by the gas became smaller, thereby reducing the velocity of the airflow. These results are consistent with the simulation results of previous authors studying fly ash impulse air dryers (Liang et al. 2017). When the wood flour entered the dryer, the velocity of the airflow was reduced to a certain extent.

As shown in Fig. 4b, the maximum velocity of the particles was $11.6 \mathrm{~m} / \mathrm{s}$, which was a $2 \mathrm{~m} / \mathrm{s}$ difference from the maximum airflow velocity. The velocity difference between the gas-solid phase strengthens the convection in the system, which helps to 
increase the drying rate and effect of lignocellulosic flours. Therefore, the velocity difference between the gas-solid phase strengthened the convective effect of the wood flour and hot air. This effect improved the drying rate of the wood flour.

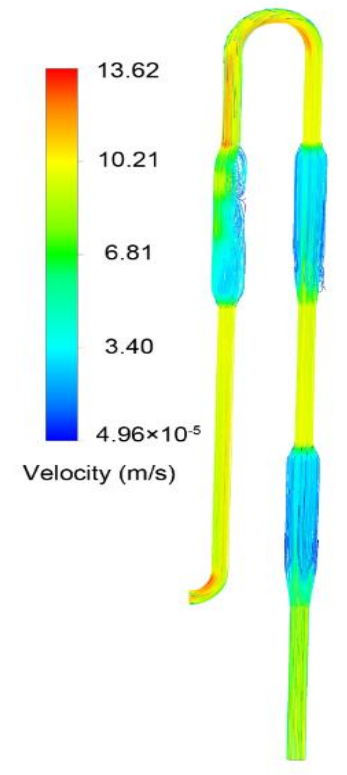

(a)

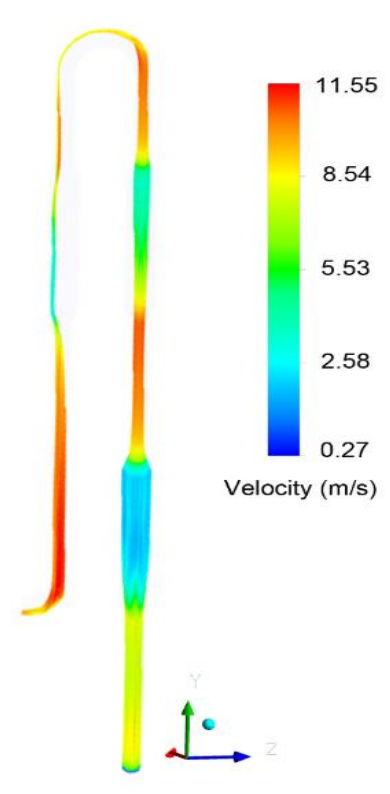

(b)

Fig. 4. Particle velocity simulation results of the ICAD system: (a) Air velocity of the ICAD system when loading particles; and (b) Particle velocity of the ICAD system

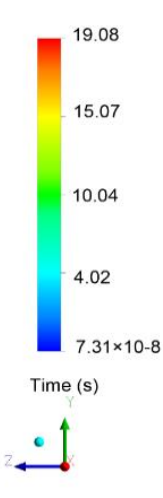

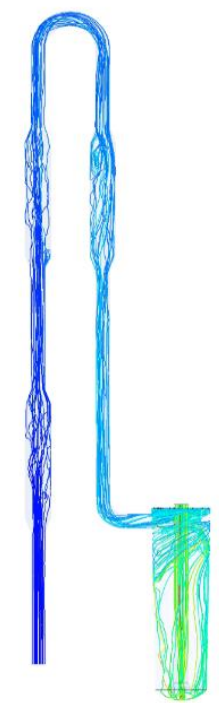

(a)

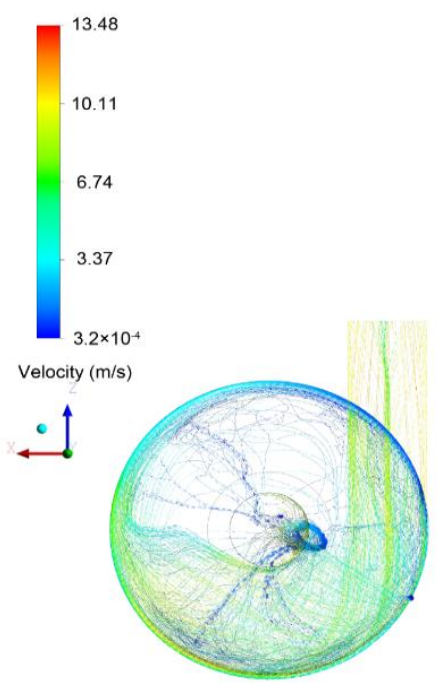

(b)

Fig. 5. Particle trajectory of the ICAD system: (a) Particle residence time of the ICAD system; and (b) Streamline of the particle velocity in the cyclone dryer

Figure 5a shows the residence time of the particles in the ICAD system. The maximum residence time of the wood flour in the dryer was $19.1 \mathrm{~s}$, of which the minimum residence time in the impulse tube was $4.2 \mathrm{~s}$ and the residence time in the cyclone tube was 
14.9 s. At the drying tube inlet, the wood flour with an initial velocity of zero was accelerated via hot air with a high velocity. Meanwhile, because there were more particles processed here, i.e., the heat transfer surface area was the largest, the heat and mass transfer coefficient of the inlet section was larger than the subsequent dry section. Therefore, the drying process occurring at the drying inlet section had the greatest influence on the entire drying efficiency.

Figure $5 \mathrm{~b}$ represents the streamline of the velocity of poplar flour in the cyclone dryer. The hot air and poplar flour entered the top of the cyclone dryer at a high speed in a tangential direction. Since the inner tube hindered the airflow movement, turbulence formed at the inlet of the inner tube; this caused wood flour at this point to move around the vortex center with the airflow. Consequently, this enhanced heat transfer efficiency.

\section{Airflow and Temperature Change of the Particles in the Impulse-Cyclone Airflow Drying System}

Figure 6a shows the temperature change of the hot air flow. Figure $6 \mathrm{~b}$ shows the temperature change of the particles along the length of the impulse dryer. The temperature of the airflow kept dropping from the inlet to the second stage of the extension tube, and the hot air flow finally out-flowed at a temperature of $181{ }^{\circ} \mathrm{C}$. The temperature of the particles increased from 26 to $163{ }^{\circ} \mathrm{C}$ at the outlet. During the entire drying process, the airflow temperature remained higher than the temperature of the particles. The final temperature difference between the temperature of the particles and the airflow was $18{ }^{\circ} \mathrm{C}$ at the second extension tube, which indicated that continuing to increase the length of the tube had little effect on the drying efficiency of the impulse dryer.

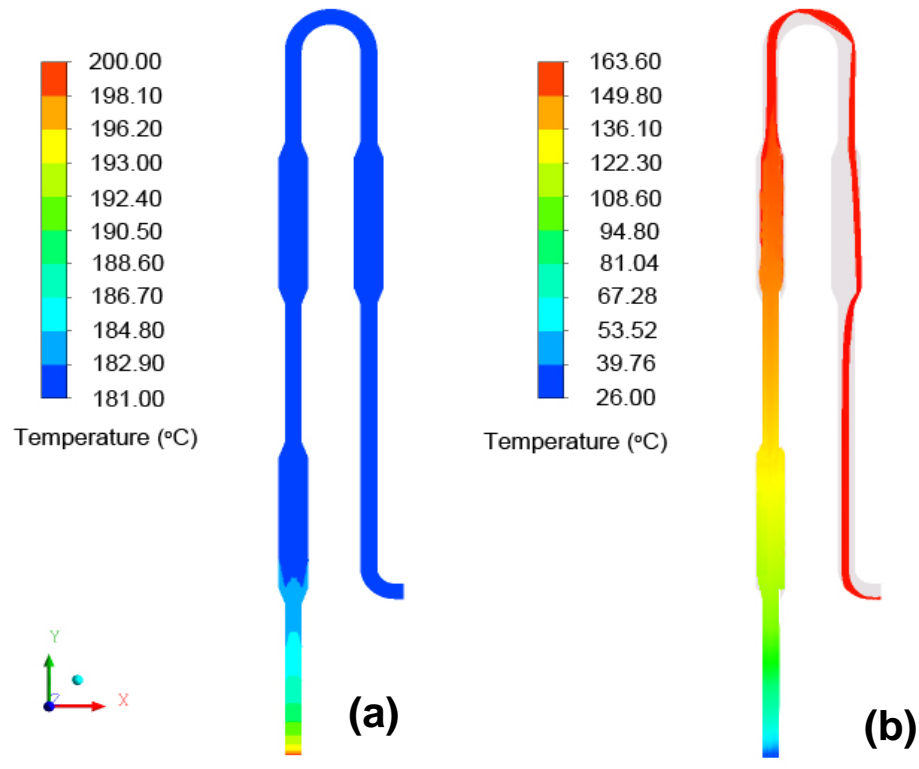

Fig. 6. Temperature clouds of the impulse dryer profile: (a) temperature change cloud of the airflow; and (b) temperature change cloud of the particles

Due to the heat exchange between the hot air and wood flour, the temperature of the hot air gradually decreased, and the temperature of the poplar flour gradually increased. The heat was transferred from the surrounding environment to the surface of the wood 
flour, causing the moisture on the surface to evaporate, started during the beginning stage of drying. Following this, the evaporated water was removed from the surface of the poplar flour in the form of steam. The drying rate in this process depended on the particle temperature and air temperature. The authors note that it is particularly important to exclude moisture. The moisture on the surface of the wood flour diffused to the surroundings in the form of steam through the air film on the surface. This mass transfer process was accompanied by heat transfer; this enhancement of heat transfer helps accelerate the drying of the flour.

\section{Effect of the Feed Rate on the Impulse-Cyclone Airflow Drying of a Gas- solid Two-phase Flow}

Figure 7 presents the solid phase motion trajectories from different feed rate conditions, i.e., $0.025,0.029,0.033,0.038$, and $0.041 \mathrm{~kg} / \mathrm{s}$. The number of particles displayed in Fluent was set to 50, and each streamline represented the trajectory of an individual particle. A larger feed rate caused a greater turbulent motion in the airflow, which corresponded to a greater probability of collisions between the particles. Increasing the feed rate also caused material backflow at the bottom of the cyclone dryer, which resulted in the wood flour having difficulty discharging from the outlet. When the feeding rate was $0.041 \mathrm{~kg} / \mathrm{s}$, the material backflow was stronger at the inner tube, and only a small amount of material outflowed from the outlet.

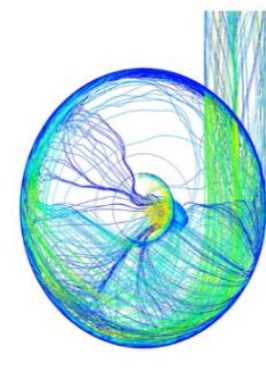

(a)

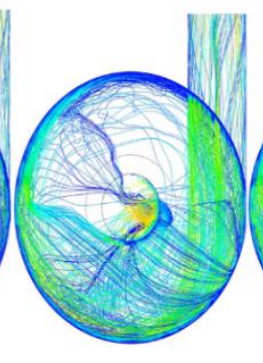

(b)

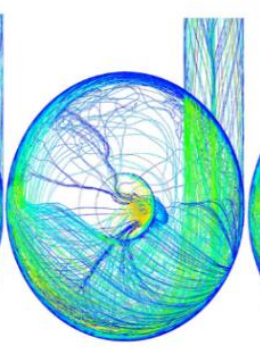

(c)

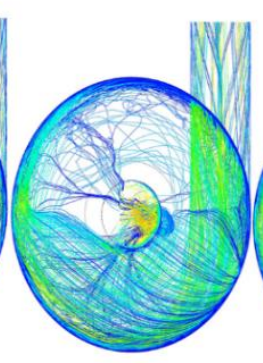

(d)

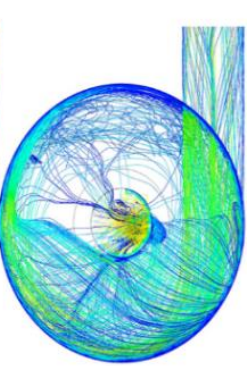

(e)

Fig. 7. The effect of different feed rates on wood flour movement in a cyclone dryer at feed rates of: (a) $0.025 \mathrm{~kg} / \mathrm{s}$; (b) $0.029 \mathrm{~kg} / \mathrm{s}$; (c) $0.033 \mathrm{~kg} / \mathrm{s}$; (d) $0.038 \mathrm{~kg} / \mathrm{s}$; and (e) $0.041 \mathrm{~kg} / \mathrm{s}$ (Chen et al. 2017a)

\section{Effect of the Inlet Airflow Velocity on Gas-solid Two-phase Flow}

A lower inlet airflow velocity can prolong the gas-solid contact time, which is beneficial to drying. However, in order to ensure discharge efficiency, the wood flour must be transported at a certain high-velocity airflow. Inlet airflow velocities of 5, 7, 9, 11, and $13 \mathrm{~m} / \mathrm{s}$ were used to analyze the airflow velocity relationship between the gas and solid phases.

In the entrance acceleration section and the cyclone inner tube rising section, the relative gas-solid velocity difference was large at the initial movement; this caused a large drag force. The particle gravity was less than the sum of the buoyancy and drag force, thus, the particles were continuously accelerated upward. As the particle velocity increased, the drag force gradually decreased. When gravity was equal to the sum of the buoyancy and drag forces, the constant velocity movement of the particles began. In the deceleration 
section of the impulse dryer, as the airflow velocity continued to decrease, the drag force was reduced. When the air velocity was greater than the particle velocity and the direction of the drag force was upward, the gravity was greater than the sum of the buoyancy and drag force. If gravity was equal to the sum of the buoyancy and drag, the particles moved upward at a constant speed. In contrast, if gravity was greater than the sum of the buoyancy and drag, the speed of the particles decreased to zero; consequently, the material could not be discharged.

At the bottom of the cyclone dryer, when the wood flour rotated down to the bottom of the cyclone dryer, the wood flour was redistributed. This caused a large speed difference between the gas and the solid particles and resulted in strong heat transfer and mass transfer on the surface of the solid particles. The rotational movement of the flour before entering the inner tube was irregular turbulence with a back-mixing phenomenon. The shape of the inner tube had a certain guiding effect on the rotation of the particles. At this time, the particle was affected by gravity, buoyancy, Magnus lift, and drag. Under the condition that the values of the buoyancy, Magnus lift, and drag are greater than gravity, the flour accelerates and rotates (Wang et al. 2019) When the buoyancy, Magnus lift, and drag are equal to the value of gravity, the particles rotated at a uniform speed. However, when the values of the buoyancy, Magnus lift, and drag are less than gravity, the particles directly settled at the bottom of the dryer. Due to this, a spare discharge port needed to be added at the bottom of the dryer.

It can be seen in Fig. 8 that when the airflow velocity is low, the particles settled quickly in the cyclone dryer, and the turbulent movement and backflow phenomenon at the bottom to the inner tube inlet were obvious. When the airflow velocity was $5 \mathrm{~m} / \mathrm{s}$, even though the air velocity was greater than the material velocity, gravity was greater than the buoyancy, drag, and Magnus Lift; consequently, the particles settled directly at the bottom of the dryer and did not escape.

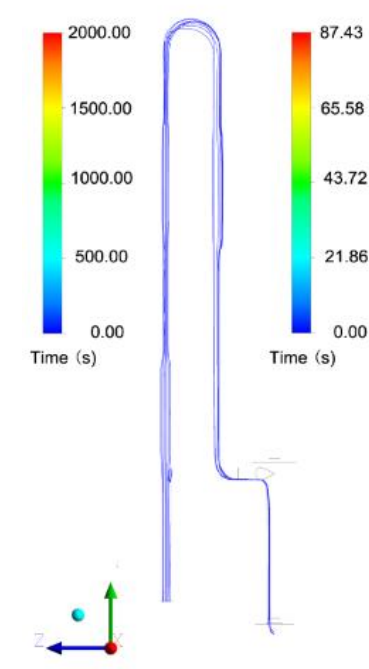

(a)

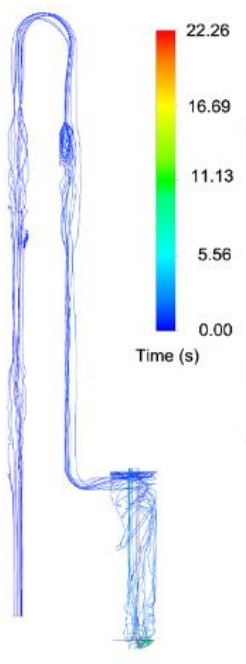

(b)

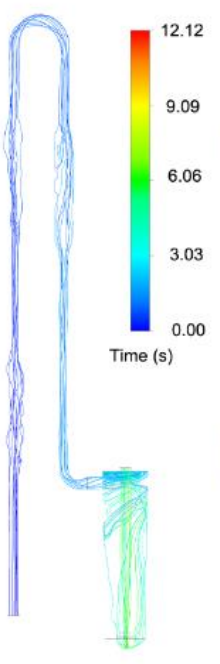

(c)

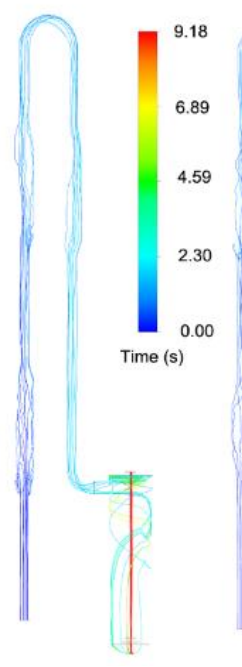

(d)

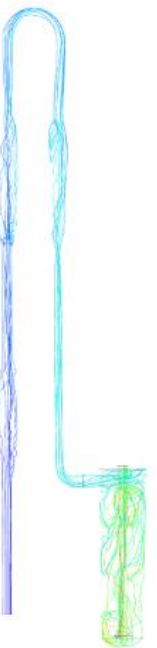

(e)

Fig. 8. The wood flour retention times under different inlet airflow velocities: (a) $5 \mathrm{~m} / \mathrm{s}$; (b) $7 \mathrm{~m} / \mathrm{s}$; (c) $9 \mathrm{~m} / \mathrm{s}$; (d) $11 \mathrm{~m} / \mathrm{s}$; and (e); $13 \mathrm{~m} / \mathrm{s}$. 


\section{Flow Effect of the Particle Morphology on the Impulse-cyclone Airflow Drying (ICAD) Gas-solid Two-phase Flow}

Figure 9 shows the movement track of particles with diameters of 178, 192, 223, 283 , and $330 \mu \mathrm{m}$, with corresponding aspect ratios of 5.4, 5.4, 6.1, 4.9, and 3.6, all with an inlet velocity of $10 \mathrm{~m} / \mathrm{s}$. The movement trajectories were highly dependent on the particle diameter. As the size of the diameter of the particles increased, the movement times of the wood flour in the impulse dryer also increased $(14.29,16.55,22.26,38.33$, and $42.00 \mathrm{~s})$. As the particle size of the wood flour increased, the centrifugal force of the flour increased, and the effect of gravity gradually became more prominent. This resulted in particles reaching the bottom of the dryer earlier in the cyclone dryer. However, large-sized wood flour particles aggregated at the bottom of the cyclone-dryer; the presence of backflow in the middle of the bottom section caused aggregated particles to move around the vortex. This resulted in large particles having long retention times, while smaller particles were being discharged out of the inner tube.

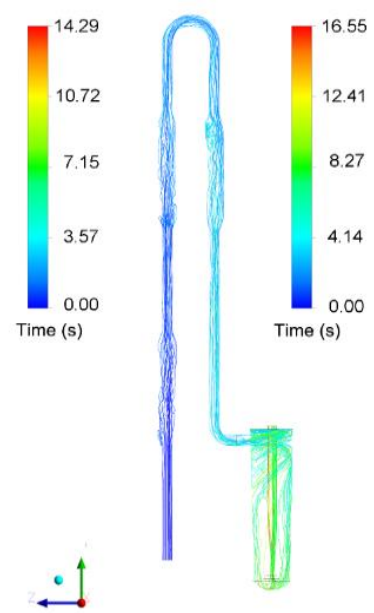

(a)

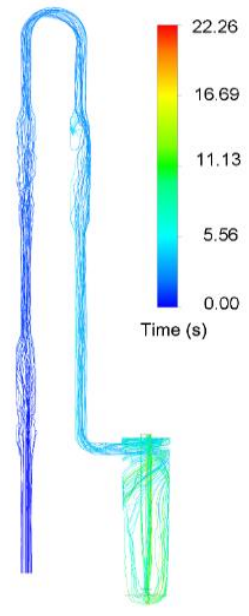

(b)

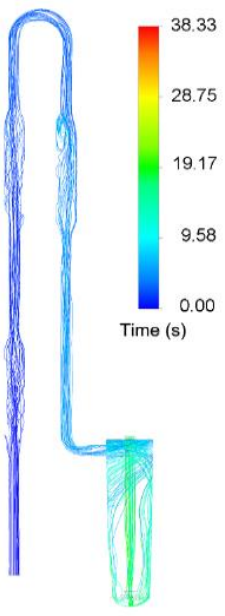

(c)

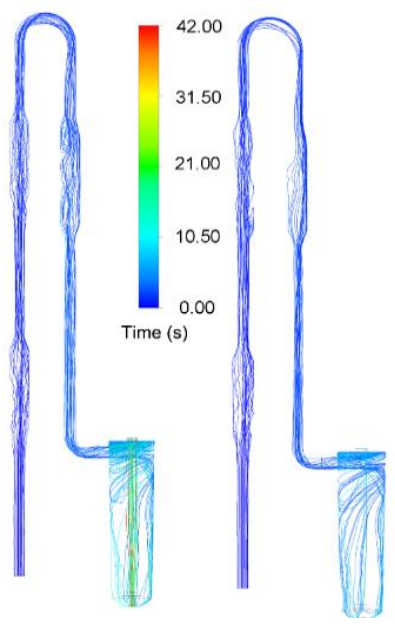

(d)

(e)

Fig. 9. Particle retention time based on different morphologies, i.e., particle diameters: (a) 178 $\mu \mathrm{m}$; (b) $192 \mu \mathrm{m}$; (c) $223 \mu \mathrm{m}$; (d) $283 \mu \mathrm{m}$; and (e) $330 \mu \mathrm{m}$

\section{Numerical Simulation Verification}

Anemometer and temperature sensors were used to measure the airflow velocity and temperature of the system at 4 observation points. Wood flour $(20 \mathrm{~kg})$ was put into the screw feeder and the dryer was started. The difference between the feeding time and discharge time were calculated. Figure 10 shows the residence time of the particles at different airflow velocities and feed rates. The simulation results reflected the experimental residence time of the wood flour well.

This is at least in part because the numerical simulation assumes that the wall surface of the drying system was adiabatic and neglects heat loss. The gas-solid phase passed through subsequent cyclones and dust removal equipment, and the temperature and velocity would decrease. However, the relative error between the calculated value and the measured value was less than $10 \%$, and the trends were consistent. The authors conclude that the calculation results of the gas-solid two-phase flow simulation of the impulse and cyclone drying using the Eulerian-Lagrangian model are credible. 


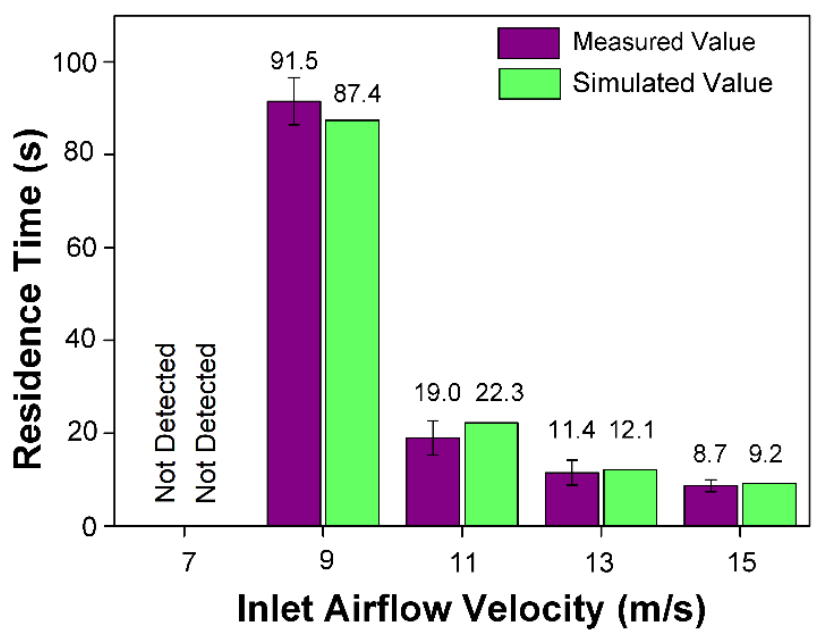

(a)

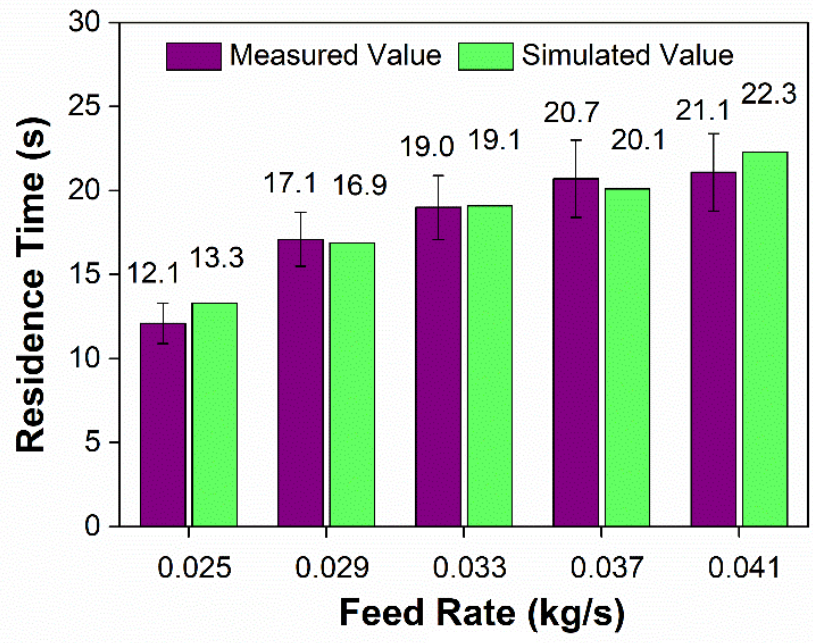

(b)

Fig. 10. Comparison of the simulation results and the measured values of the residence time under different feed rates and different inlet airflow velocities

The velocity y-coordinate components of the fluid and particles from the inlet to the expansion tube in the impulse dryer are described in Fig. 11. For small sized particles (Fig. 11b), in the simulation, the maximum velocity of particle acceleration was 1.7 times faster than the maximum velocity of the fluid. For larger particles, the velocity difference was small. The numerical results and experimental results of the airflow velocity for both the numerical and experimental results matched reasonably well. 


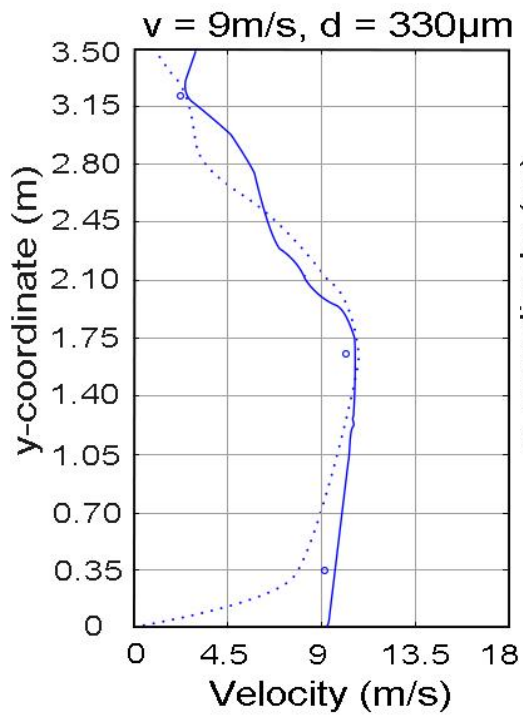

(a)

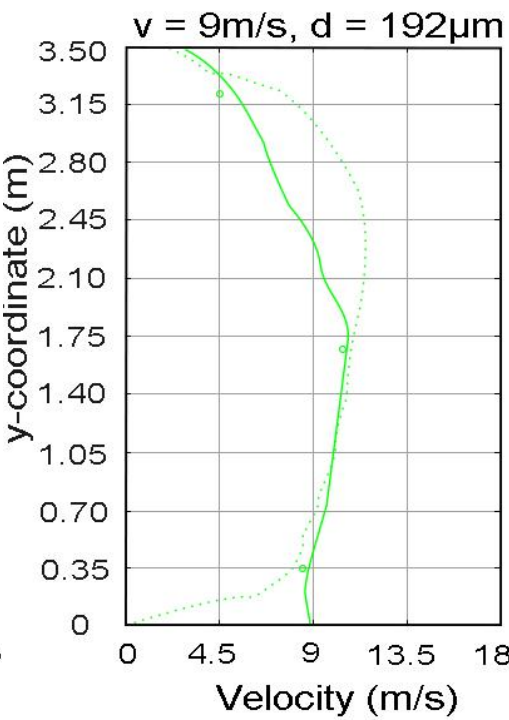

(b)

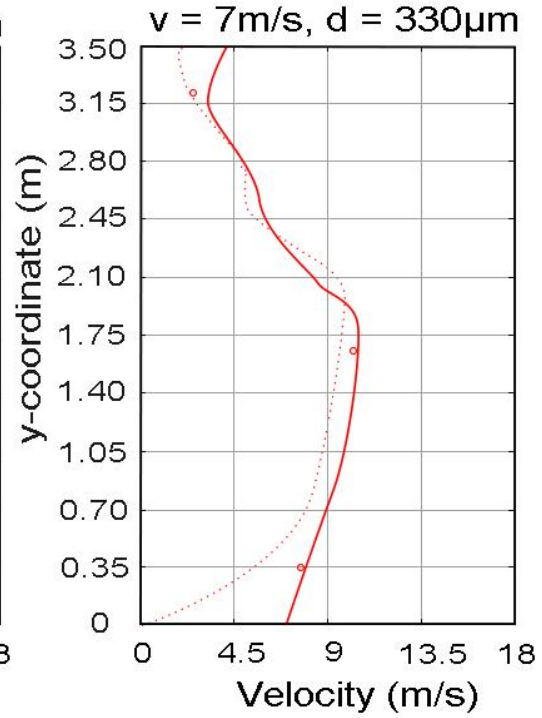

(c)

Fig. 11. The simulated air flow velocity (solid lines) vs. the simulated particle velocity (dotted lines) of the $y$-coordinate in the first straight tube and expansion tube (Note: circles represent experimental data)

\section{CONCLUSIONS}

1. The computational fluid dynamics (CFD) simulation indicated that the EulerianLagrangian algorithm model effectively described the gas-solid two-phase flow field in an impulse-cyclone airflow drying system. A vortex was formed at the nozzle of the cyclone dryer, which caused backflow.

2. Discrete phase model analysis showed that the trajectory of the particles in the dryer were largely random and moved turbulently at the bottom of the dryer. Most of the particles rotated consistently around the entrance of the inner tube retaining ring, which reflected that the inner tube retaining ring acted as a guide. The airflow at the inlet interacted with the wet particles, causing its temperature to decrease and the particle temperature to increase. The drying effect was most obvious at the inlet. The final temperature difference between the material and the airflow temperature was $18{ }^{\circ} \mathrm{C}$. Increasing the length of the pipeline had little effect on the drying efficiency of the impulse dryer.

3. By comparing the relative velocity changes and temperature changes of the air flow, with and without added materials, the authors conclude that the air flow velocity considerably changed after loading the material. The velocity difference between the material and the air flow speed was approximately $2 \mathrm{~m} / \mathrm{s}$, which was conducive to heat and mass transfer. An increase in the feed rate created a reflux zone at the bottom of the cyclone dryer, which caused the material to flow back and increased the wood flour residence time in the cyclone dryer. The calculated temperature, velocity, and time curves were compared with the experimental data and was in good agreement; the 
maximum relative error was less than $10 \%$. This work helped verify the validity of using CFD with the conditions from this study to model ICAD processes with an interacting continuous gas phase and particle-based solid phase.

\section{ACKNOWLEDGMENTS}

This work was supported by the National Natural Science Foundation of China under Grant No.31901243. Feng Chen and Yinan Liu contributed to the synthesis, testing, and data analysis, and wrote the manuscript. Xinghua Xia suggested and supervised the work, and Xiaohui $\mathrm{Ni}$ revised the manuscript. Feng Chen provided constructive suggestions about this work and contributed to the characterization of the wood flour.

\section{REFERENCES CITED}

Akpinar, E., Midilli, A., Bicer, Y. (2003) "Single layer drying behaviour of potato slices in a convective cyclone dryer and mathematical modeling," Energy Conversion and Management 44(10), 1689-1705. DOI: 10.1016/s0196-8904(02)00171-1

Alavi, S. A. R., Lay, E. N., and Makhmali, Z. S. A. (2018). "A CFD study of industrial double-cyclone in HDPE drying process," Emerging Science Journal 2(1), 31-38. DOI: 10.28991/esj-2018-01125

Ávila, M. D. R. d., Hoz, L., Ordóñez, J. A., and Cambero, M. I. (2014). "Dry-cured ham restructured with fibrin," Food Chemistry 159, 519-528. DOI: 10.1016/j.foodchem.2014.03.051

Buchholz, M., Haus, J., Blesinger, L., Riemann, C., Pietsch, S., Jäger, F. K., and Heinrich, S. (2021). "Process design of a multistage drying process via flowsheet simulation," Chemie Ingenieur Technik 93(8), 1287-1294. DOI: 10.1002/cite.202000207

Bunyawanichakul, P., Kirkpatrick, M. P., Sargison, J. E., and Walker, G. J. (2006). "Numerical and experimental studies of the flow field in a cyclone dryer," Journal of Fluids Engineering128(6), 1240-1250. DOI: 10.1115/1.2354523

Chen, F., Han, G., Li, Q., Gao, X., and Cheng, W. (2017a). "High-temperature hot air/silane coupling modification of wood fiber and its effect on properties of wood fiber/HDPE composites," Materials 10(3), 1-17. DOI: 10.3390/ma10030286

Chen, F., Li, Q., Gao, X., Han, G., and Cheng, W. (2017b). "Impulse-cyclone drying treatment of poplar wood fibers and its effect on composite material's properties," BioResources 12(2), 3948-3964. DOI: 10.15376/biores.12.2.3948-3964

Chu, K. W., Kuang, S. B., Yu, A. B., Vince, A., Barnett, G. D., and Barnett, P. J. (2014). "Prediction of wear and its effect on the multiphase flow and separation performance of dense medium cyclone," Minerals Engineering 56, 91-101. DOI: 10.1016/j.mineng.2013.10.029

Fernando, N., Narayana, M., and Wickramaarachchi, W. A. M. K. P. (2017). "The effects of air velocity, temperature and particle size on low-temperature bed drying of wood chips," Biomass Conversion and Biorefinery 8, 211-223. DOI: 10.1007/s13399-0170257-7 
Gao, X., Lin, L., Pang, J., Chen, F., and Li, Q. (2019). "Effects of impulse-cyclone drying and silane modification on the properties of wood fiber/HDPE composite material," Carbohydrate Polymers 207, 343-351. DOI: 10.1016/j.carbpol.2018.11.078

Giavedoni, M. D., and Saita, F. A. (1997). "The axisymmetric and plane cases of a gas phase steadily displacing a Newtonian liquid - A simultaneous solution of the governing equations," Physics of Fluids 9(8), 2420-2428. DOI: 10.1063/1.869360

Granados, D. A., Chejne, F., and Basu, P. (2016). "A two dimensional model for torrefaction of large biomass particles," Journal of Analytical Applied Pyrolysis 120, 1-14. DOI: $10.1016 /$ j.jaap.2016.02.016

Jamaleddine, T. J., and Ray, M. B. (2011). "The drying of sludge in a cyclone dryer using computational fluid dynamics," Drying Technology 29(12), 1365-1377. DOI: 10.1080/07373937.2011.567946

Larsson, H., and Orloff, D. (2001). "Lab-scale impulse drying experiments with extension to higher impulse," Drying Technology 19(10), 2549-2558. DOI: 10.1081/DRT-100108253

Li, S., Scherer, R. C., Fulcher, L. P., Wang, X., Qiu, L., Wan, M., and Wang, S. (2017a). "Effects of vertical glottal duct length on intraglottal pressures and phonation threshold pressure in the uniform glottis," Journal of Voice 32(1), 8-22. DOI: 10.1016/j.jvoice.2017.04.002

Li, W., Zhang, Q., Wang, C., Yan, X., Shen, S., Xia, G., Zhu, F., and Zhang, J. (2017b). "Experimental and numerical analysis of a three-dimensional flow field for PEMFCs," Applied Energy 195(1), 278-288. DOI: 10.1016/j.apenergy.2017.03.008

Liang, L., Peng, Z., Zhang, S., Jia, Y., and Yu, W. (2017). "Simulation and analysis of Magnus rotating roll stabilizer at low speed," Ocean Engineering 142, 491-500. DOI: 10.1016/j.oceaneng.2017.07.012

Lin, Z., Sun, X., Yu, T., Zhang, Y., Li, Y., and Zhu, Z. (2020). "Gas-solid two-phase flow and erosion calculation of gate valve based on the CFD-DEM model," Powder Technology 366, 395-407. DOI: 10.1016/j.powtec.2020.02.050

Liu, B., Zhang, X., Wang, L., and Hong, H. (2008). "Fluidization of non-spherical particles: Sphericity, Zingg factor and other fluidization parameters," Particuology 6(2), 125-129. DOI: 10.1016/j.cpart.2007.07.005

Luo, X., Lü, G., Zhang, W., He, L., and Lü, Y. (2017). "Flow structure and pressure gradient of extra heavy crude oil-water two-phase flow," Experimental Thermal and Fluid Science 82, 174-181. DOI: 10.1016/j.expthermflusci.2016.11.015

Mansoori, Z., Saffar-Avval, M., Tabrizi, H. B., and Ahmadi, G. (2004). "Experimental study of turbulent gas-solid heat transfer at different particles temperature," Experimental Thermal and Fluid Science 28(6), 655-665. DOI: 10.1016/j.expthermflusci.2003.10.003

Nakhaei, M. H., and Lessani, B. (2017). "Effects of solid inertial particles on the velocity and temperature statistics of wall bounded turbulent flow," International Journal of Heat and Mass Transfer 106, 1014-1024. DOI: 10.1016/j.ijheatmasstransfer.2016.10.073

Patel, R. G., Desjardins, O., Kong, B., Capecelatro, J., and Fox, R. O. (2017). "Verification of Eulerian-Eulerian and Eulerian-Lagrangian simulations for turbulent fluid-particle flows," AIChE Journal 63(12), 5396-5412. DOI: 10.1002/aic.15949

Saidi, M., Tabrizi, H. B., Grace, J. R., and Lim, C. J. (2015). "Hydrodynamic investigation of gas-solid flow in rectangular spout-fluid bed using CFD-DEM modeling," Powder Technology 284, 355-364. DOI: 10.1016/j.powtec.2015.07.005 
Seifert, J. (2012). "A review of the Magnus effect in aeronautics," Progress in Aerospace Sciences 55, 17-45. DOI: 10.1016/j.paerosci.2012.07.001

Son, G., and Hur, N. (2002). "A coupled level set and volume-of-fluid method for the buoyancy-driven motion of fluid particles," Numerical Heat Transfer, Part B: Fundamentals 42(6), 523-542. DOI: 10.1080/10407790260444804

Sun, J., Zhou, Y., Ren, C., Wang, J., and Yang, Y. (2011). "CFD simulation and experiments of dynamic parameters in gas-solid fluidized bed," Chemical Engineering Science 66(21), 4972-4982. DOI: 10.1016/j.ces.2011.06.035

Yamoah, S., Martínez-Cuenca, R., Monrós, G., Chiva, S., and Macián-Juan, R. (2015). "Numerical investigation of models for drag, lift, wall lubrication and turbulent dispersion forces for the simulation of gas-liquid two-phase flow," Chemical Engineering Research Design 98, 17-35. DOI: 10.1016/j.cherd.2015.04.007

Yokosawa, M., Kozawa, Y., Inoue, A., and Aoki, S. (1986). "Studies on two-phase cross flow. Part II: Transition Reynolds number and drag coefficient," International Journal of Multiphase Flow 12(2), 169-184. DOI: 10.1016/0301-9322(86)90024-8

Yousaf, K., Liu, H., Gao, X., Liu, C., Abbas, A., Nyalala, I., Ahmad, M., Ameen, M., and Chen, K. (2019). "Influence of environmental conditions on drying efficiency and heat pump performance in closed and open loop drying of paddy," Drying Technology 38(16), 1-14. DOI: 10.1080/07373937.2019.1691011

Zaripov, T. S., Rybdylova, O., and Sazhin, S. S. (2018). “A model for heating and evaporation of a droplet cloud and its implementation into ANSYS Fluent," International Communications in Heat and Mass Transfer 97, 85-91. DOI: 10.1016/j.icheatmasstransfer.2018.06.007

Zhang, Y., and Reese, J. M. (2003). "The drag force in two-fluid models of gas-solid flows," Chemical Engineering Science 58(8), 1641-1644. DOI: 10.1016/S00092509(02)00659-0

Zhang, Y., Ran, Z., Jin, B., Zhang, Y., Zhou, C., and Sher, F. (2019). "Simulation of particle mixing and separation in multi-component fluidized bed using EulerianEulerian method: A review," International Journal of Chemical Reactor Engineering 17(11), 20190064. DOI: 10.1515/ijcre-2019-0064

Zhe, W., Aguirre, A., Tran, A., Durand, H., and Christofides, P. D. (2017). "Model predictive control of a steam methane reforming reactor described by a CFD model," Industrial Engineering Chemistry Research 56(20), 6002-6011. DOI: 10.1021/acs.iecr.7b00390

Zhou, H., St. John, F., and Zhu, J.Y. (2019). "Xylanase pretreatment of wood fibers for producing cellulose nanofibrils: a comparison of different enzyme preparations," Cellulose 26, 543-555. DOI: 10.1007/s10570-019-02250-1

Article submitted: September 11, 2021; Peer review completed: October 17, 2021; Revised version received and accepted: October 21, 2021; Published: November 8, 2021. DOI: 10.15376/biores.17.1.75-93 